Correspondence:

kinga_bujakowska

@meei.harvard.edu

(C) 2020 Scott et al. This article is distributed under the terms of the Creative Commons

Attribution-NonCommercial License, which permits reuse and redistribution, except for commercial purposes, provided that the original author and source are credited.

Ontology terms: central scotoma; cone-rod dystrophy; macular dystrophy; peripheral visual field loss; pigmentary retinal degeneration; progressive central visual loss; progressive visual field defects; severe visual impairment

Published by Cold Spring Harbor Laboratory Press

doi:10.1101/mcs.a004754

\section{Expanding the phenotypic spectrum in RDH12-associated retinal disease}

\author{
Hilary A. Scott, ${ }^{1}$ Emily M. Place, ${ }^{1}$ Kevin Ferenchak, ${ }^{1}$ Erin Zampaglione, ${ }^{1}$ \\ Naomi E. Wagner, ${ }^{1}$ Katherine R. Chao, ${ }^{2}$ Stephanie P. DiTroia, ${ }^{2}$ \\ Daniel Navarro-Gomez, ${ }^{1}$ Shizuo Mukai, ${ }^{3}$ Rachel M. Huckfeldt, ${ }^{1}$ Eric A. Pierce, ${ }^{1}$ \\ and Kinga M. Bujakowska ${ }^{1}$ \\ ${ }^{1}$ Ocular Genomics Institute, Department of Ophthalmology, Massachusetts Eye and Ear, Harvard Medical \\ School, Boston, Massachusetts 02114, USA; ${ }^{2}$ Center for Mendelian Genetics, Broad Institute of MIT and \\ Harvard, Cambridge, Massachusetts 02142, USA; ${ }^{3}$ Retina Service, Department of Ophthalmology, \\ Massachusetts Eye and Ear, Harvard Medical School, Boston, Massachusetts 02114, USA
}

\begin{abstract}
Retinol dehydrogenase 12, RDH12, plays a pivotal role in the visual cycle to ensure the maintenance of normal vision. Alterations in activity of this protein result in photoreceptor death and decreased vision beginning at an early age and progressing to substantial vision loss later in life. Here we describe 11 patients with retinal degeneration that underwent next-generation sequencing (NGS) with a targeted panel of all currently known inherited retinal degeneration (IRD) genes and whole-exome sequencing to identify the genetic causality of their retinal disease. These patients display a range of phenotypic severity prompting clinical diagnoses of macular dystrophy, cone-rod dystrophy, retinitis pigmento$\mathrm{sa}$, and early-onset severe retinal dystrophy all attributed to biallelic recessive mutations in RDH12. We report 15 causal alleles and expand the repertoire of known RDH12 mutations with four novel variants: c.215A > G (p.Asp72Gly); c.362T >C (p.lle121Thr); c.440A >C (p.Asn147Thr); and c.697G >A (p.Val233llle). The broad phenotypic spectrum observed with biallelic RDH12 mutations has been observed in other genetic forms of IRDs, but the diversity is particularly notable here given the prior association of $\mathrm{RDH} 12$ primarily with severe early-onset disease. This breadth emphasizes the importance of broad genetic testing for inherited retinal disorders and extends the pool of individuals who may benefit from imminent gene-targeted therapies.
\end{abstract}

[Supplemental material is available for this article.]

\section{INTRODUCTION}

Retinol dehydrogenase 12 (RDH12) is a member of a short-chain dehydrogenase/reductase superfamily highly expressed in the photoreceptors (Maeda et al. 2006; Kurth et al. 2007). RDH12 and RDH8, another enzyme from the same family, convert all-trans-retinal to alltrans-retinol, which is a crucial step in the vitamin A cycle, also called the visual cycle (Haeseleer et al. 2002; Belyaeva et al. 2005; Parker and Crouch 2010). RDH8, localized in the photoreceptor outer segments, converts most of the all-trans-retinal necessary for the visual cycle, whereas RDH12, localized in the inner segments, is crucial for the reduction of alltrans-retinal in the inner segments preventing the buildup of toxic aldehydes. Accumulation of these aldehydes is thought to be the major cause of photoreceptor cell loss, as mutations in RDH12 and not RDH8 have been associated with disease (Thompson et al. 2005; Maeda et al. 2007; Marchette et al. 2010; Chen et al. 2012). 
COLD SPRING HARBOR Molecular Case Studies
Novel phenotype associated with RDH12 mutations
Mutations in RDH12 were first discovered to cause a recessive form of Leber congenital amaurosis (LCA), which is an early-onset retinal degeneration (Stockton et al. 1998; Janecke et al. 2004; Perrault et al. 2004). RDH12-associated disease is thought to account for up to $4 \%$ of LCA cases (Perrault et al. 2004). Subsequently, mutations in RDH12 have been found in patients with autosomal recessive (AR) retinitis pigmentosa (RP) as well as cone-rod dystrophies (CORDs) (Janecke et al. 2004; Chacon-Camacho et al. 2013; Huang et al. 2016). Characteristics of disease caused by recessive biallelic mutations in RDH12 include early-onset progressive degeneration of both rods and cones with severely reduced or extinguished responses on electroretinogram (ERG) (Schuster et al. 2007). A dominant form of RDH12 disease has also been reported (Fingert et al. 2008).

Here we present eleven cases of recessive RDH12-associated disease with variable age of onset and severity as well as widening the phenotypic spectrum of RDH12-associated disease to include macular dystrophy. Using whole-exome sequencing (WES) and next-generation sequencing (NGS) panel testing specific for inherited retinal degeneration (IRD) genes (Consugar et al. 2014) versus sequencing based on rigid phenotypes allowed the diagnosis of patients with milder retinal degeneration phenotypes less commonly associated with RDH12 mutations. We also report four novel variants expanding the catalog of causal variants in $\mathrm{RDH} 12$.

\section{RESULTS}

\section{Genomic Analysis}

Analysis of 11 patients with retinal degeneration by WES and NGS panel testing identified 16 missense mutations in RDH12, of which four missense variants were novel (Tables 1 and 2). When possible, segregation analysis was performed with available family members, otherwise variants were confirmed to be in trans either by NGS paired-end reads or cloning of a large fragment followed by Sanger sequencing (Supplemental Fig. S1). Mutations found in the present study span the entire length of the protein, residing in regions vital to the underlying function of the RDH12 enzyme, including nucleotide-binding regions and catalytic regions (Fig. 1A). The novel missense variants—c.215G > A (p.Asp72Gly) (exon 3) c.362T > C (p.lle121Thr), c.440A > C (p.Asn147Thr) (exon4), and c.697G > A (p.Val233Ille) (exon 6)—all reside within the RDH12 catalytic domain (Fig. 1A). They were predicted to be damaging according to in silico predictions and were either extremely rare (MAF <0.001) or not present in gnomAD (Tables 1 and 2; Karczewski et al. 2019) as well as their respective amino acid positions being highly conserved (Fig. 1B).

All of the reported subjects carried rare variants in other IRD genes; however, these were not considered as causal as they were either single alleles in autosomal recessive genes or too common to be causative of autosomal dominant forms of IRDs (Supplemental Table S1). Of interest, two subjects were identified to have one heterozygous variant in the gene ABCA4. For one case, OGI3076-4666, this finding initially led to a diagnosis of Stargardt disease. After NGS panel sequencing, no other potentially causal ABCA4 variants were found for this subject, and although this gene is enriched with deep intronic noncoding mutations (Bax et al. 2015; Schulz et al. 2017; Albert et al. 2018), the clinical and genetic findings pointed to compound heterozygous RDH12 mutations c.619A > G (p.Asn207Asp) and c.697G > A (p.Val233lle) as the likely cause of disease. Similarly, we did not detect a second causal ABCA4 allele in subject OGI3077-4669 or likely pathogenic mutations in other IRD genes (Supplemental Table S1).

\section{Clinical Presentations}

Eleven subjects were seen at the Retina or Inherited Retinal Disorders Services at Massachusetts Eye and Ear between 1979 and 2019, with follow-up data available for seven 


\begin{tabular}{|c|c|c|c|c|c|c|c|c|}
\hline Sample ID & Diagnosis & $\begin{array}{l}\text { cDNA } \\
\text { change }\end{array}$ & $\begin{array}{l}\text { Protein } \\
\text { change }\end{array}$ & $\begin{array}{l}\text { CADD } \\
\text { score }\end{array}$ & ACMG & Segregation & GnomAD & Published \\
\hline \multirow[t]{2}{*}{ OGI519-1068 } & \multirow[t]{2}{*}{$\mathrm{MD}$} & c. $701 \mathrm{G}>\mathrm{A}$ & p.Arg234His & 12.04 & LP & \multirow{2}{*}{$\begin{array}{l}\text { Determined by paired-end } \\
\text { NGS reads } \\
\text { (Supplemental Fig. S1a) }\end{array}$} & 0.000099 & $\begin{array}{l}\text { Thompson } \\
\text { et al. } 2005\end{array}$ \\
\hline & & c. $844 \mathrm{~T}>\mathrm{G}$ & p.Phe282Val & 32.0 & LP & & 0.000004 & $\begin{array}{l}\text { Consugar } \\
\text { et al. } 2014\end{array}$ \\
\hline \multirow[t]{2}{*}{ OGI3079-4672 } & \multirow[t]{2}{*}{$\mathrm{MD}$} & c. $185 \mathrm{G}>\mathrm{T}$ & p.Arg62Leu & 34 & LP & \multirow{2}{*}{$\begin{array}{l}\text { Determined by cloning } \\
\text { and Sanger } \\
\text { (Supplemental Fig. S1b) }\end{array}$} & 0.0001747 & $\begin{array}{l}\text { Fahim et al. } \\
2019\end{array}$ \\
\hline & & c. $619 A>G$ & p.Asn207Asp & 25.8 & LP & & 0.000007964 & $\begin{array}{l}\text { Mackay et al. } \\
2011\end{array}$ \\
\hline \multirow[t]{2}{*}{ OGI2933-4518 } & \multirow[t]{2}{*}{$\mathrm{MD}$} & c. $440 \mathrm{~A}>\mathrm{C}$ & p.Asn147Thr & 28.1 & $P$ & \multirow{2}{*}{$\begin{array}{l}\text { Determined by cloning } \\
\text { and Sanger } \\
\text { (Supplemental Fig. S1c) }\end{array}$} & 0.000003977 & This study \\
\hline & & c. $701 \mathrm{G}>\mathrm{A}$ & p.Arg234His & 12.04 & LP & & 0.000099 & $\begin{array}{l}\text { Thompson } \\
\text { et al. } 2005\end{array}$ \\
\hline \multirow[t]{2}{*}{ OGI3076-4666 } & \multirow[t]{2}{*}{ CORD } & c. $619 A>G$ & p.Asn207Asp & 25.8 & LP & Paternal & 0.000007964 & $\begin{array}{l}\text { Mackay et al. } \\
2011\end{array}$ \\
\hline & & c. $697 \mathrm{G}>\mathrm{A}$ & p.Val233Ile & 20.5 & $P$ & Maternal & 0.0 & This study \\
\hline \multirow[t]{2}{*}{ OGI2356-3915 } & \multirow[t]{2}{*}{ EORD } & c. $194 \mathrm{G}>\mathrm{A}$ & p.Arg65Gln & 32.0 & VUS & \multirow[t]{2}{*}{ N/A } & 0.00001768 & $\begin{array}{l}\text { Thompson } \\
\text { et al. } 2005\end{array}$ \\
\hline & & c. $506 \mathrm{G}>\mathrm{A}$ & p.Arg169Gln & 27.4 & LP & & 0.00001193 & $\begin{array}{l}\text { Mackay et al. } \\
2011\end{array}$ \\
\hline OGI1611-2841 & $\mathrm{RP}$ & c. $146 C>T$ & p.Thr49Met & 28.0 & $P$ & Hom & 0.00001768 & $\begin{array}{l}\text { Janecke et al. } \\
2004\end{array}$ \\
\hline OGI3077-4669 & EORD & c. $146 C>T$ & p.Thr49Met & 28.0 & $P$ & $\begin{array}{l}\text { Hom (unaffected brother } \\
\text { het) }\end{array}$ & 0.00001768 & $\begin{array}{l}\text { Janecke et al. } \\
2004\end{array}$ \\
\hline \multirow[t]{2}{*}{ OGI1662-2892 } & \multirow[t]{2}{*}{ EORD } & c. $164 \mathrm{C}>\mathrm{T}$ & p.Thr55Met & 28.0 & LP & \multirow{2}{*}{$\begin{array}{l}\text { Determined by paired-end } \\
\text { NGS reads } \\
\text { (Supplemental Fig. S1d) }\end{array}$} & 0.00002386 & $\begin{array}{l}\text { Thompson } \\
\text { et al. } 2005\end{array}$ \\
\hline & & c. $184 \mathrm{C}>\mathrm{T}$ & p.Arg62* & 35.0 & $P$ & & 0.00005659 & $\begin{array}{l}\text { Janecke et al. } \\
2004\end{array}$ \\
\hline \multirow[t]{2}{*}{ OGI1613-2843 } & \multirow[t]{2}{*}{$\mathrm{RP}$} & c. $215 A>G$ & p.Asp72Gly & 28.0 & LP & \multirow{2}{*}{$\begin{array}{l}\text { Determined by cloning } \\
\text { and Sanger } \\
\text { (Supplemental Fig. S1e) }\end{array}$} & & This study \\
\hline & & c. $524 \mathrm{C}>\mathrm{T}$ & p.Ser175Leu & 26.0 & LP & & 0.000045 & $\begin{array}{l}\text { Coppieters } \\
\text { et al. } 2010\end{array}$ \\
\hline \multirow[t]{2}{*}{ OGI1610-2840 } & \multirow[t]{2}{*}{$\mathrm{RP}$} & c. $362 \mathrm{~T}>\mathrm{C}$ & p.lle121Thr & 26 & LP & \multirow{2}{*}{$\begin{array}{l}\text { Determined by cloning } \\
\text { and Sanger } \\
\text { (Supplemental Fig. S1f) }\end{array}$} & 0.0 & This study \\
\hline & & c. $883 \mathrm{C}>\mathrm{T}$ & p.Arg295* & 39 & LP & & 0.000018 & $\begin{array}{l}\text { Thompson } \\
\text { et al. } 2005\end{array}$ \\
\hline OGI1242-2406 & CORD & c. $295 C>A$ & p.Leu99lle & 23.8 & $P$ & Hom & 0.00006 & $\begin{array}{l}\text { Perrault et al. } \\
2004\end{array}$ \\
\hline
\end{tabular}

Bold entries are novel variants found in this study.

(MD) Macular dystrophy, (CORD) cone-rod dystrophy, (EORD) early-onset severe retinal dystrophy, (RP) retinitis pigmentosa, (CADD) combined annotation dependent depletion, (ACMG) American College of Medical Genetics and Genomics with variant classifications of (P) pathogenic, (LP) likely pathogenic, or (VUS) variant of unknown significance, (NGS) next-generation sequencing, (gnomAD) Genome Aggregation Database.

individuals (Table 3). Age at reported symptom onset ranged from 2 to $26 \mathrm{yr}$ (mean $=9.5$ ) with decreased central vision and nyctalopia as common initial complaints. All subjects had decreased visual acuity at initial presentation, and progressive vision loss to hand motion or worse was observed in cases when follow-up was possible over many decades. Goldmann perimetry was performed in nine individuals with findings ranging from isolated central scotomas to retention of central sensitivity only. Full-field ERG findings showed non-detectable rod and severely reduced cone responses in most patients (Table 3).

Two individuals with normal full-field ERGs, OGI519-1068 and OGI3079-4672, were notable for macula-predominant disease based on functional and anatomic data (Table 3; Fig. 2A-F). One (OGI519-1068) noticed blurry central vision at age 6 and demonstrated maculaonly disease on retinal imaging between ages 8 and 14 (Fig. 2A-C) with visual fields notable 
Table 2. In silico analysis of novel variants

\begin{tabular}{|c|c|c|c|c|c|c|}
\hline & \multicolumn{3}{|c|}{ Amino acid change } & \multicolumn{3}{|c|}{ Conservation } \\
\hline & SIFT & Mutation Taster & PolyPhen-2 & GERP & PhastCon & PhyloP \\
\hline c. $215 A>$ G p.(Asp72Gly) & Deleterious 0.03 & Disease causing 1.00 & Possibly damaging 0.948 & Conserved 5.65 & $\begin{array}{c}\text { Conserved } \\
0.999\end{array}$ & $\begin{array}{c}\text { Conserved } \\
4.839\end{array}$ \\
\hline c.362T > C p.lle121Thr & Deleterious 0 & Disease causing 1.00 & Probably damaging 0.979 & Conserved 6.04 & Conserved 1 & $\begin{array}{c}\text { Conserved } \\
5.252\end{array}$ \\
\hline c.440A > C p.Asn147Thr & Deleterious 0 & Disease causing 1.00 & Probably damaging 1.00 & Conserved 6.040 & Conserved 1 & $\begin{array}{c}\text { Conserved } \\
5.253\end{array}$ \\
\hline c.697G > A p.Val2331le & Deleterious 0 & Disease causing 1.00 & Probably damaging 0.999 & Conserved 5.74 & Conserved 1 & $\begin{array}{c}\text { Conserved } \\
6.212\end{array}$ \\
\hline
\end{tabular}

Prediction of pathogenicity of novel variants in $\mathrm{RDH} 12$.

(SIFT) Sorting Intolerant from Tolerant, (PolyPhen-2) Polymorphism Phenotyping version 2, (GERP) genomic evolutionary rate profiling

A

RDH12 gene

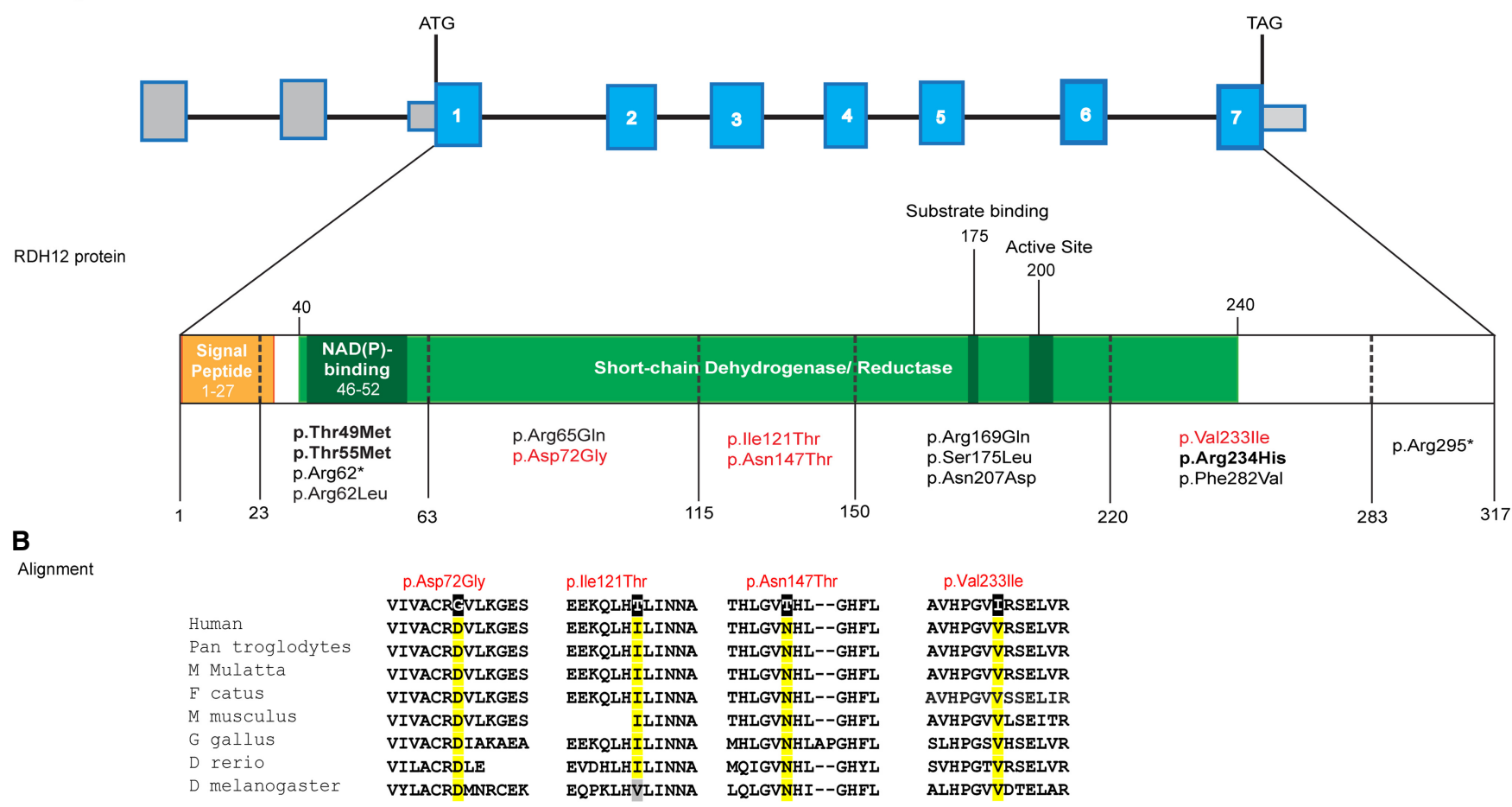

Figure 1. RDH12 protein and alignment. (A) Mutations identified in this study listed with gene and protein structure. Novel mutations appear in red; variants that have been functionally validated previously are in bold. The RDH12 gene (top) with coding exons is shaded in blue. Protein (below) is shown with dashed lines demarcating exon boundaries with amino acids numbered. $\mathrm{NAD}(\mathrm{P}) \mathrm{H}$ binding is shown in the dark green square (46-52 aa); the area in green shows the short-chain dehydrogenase/reductase homology (40-243) with active site (175 aa) and proton acceptor (200 aa) in dark green. Proposed signal peptide shown in yellow (1-27 aa). Domains and motifs defined by https://www.ebi.ac.uk/interpro/protein/Q96NR8 and http://pfam .xfam.org/protein/Q96NR8. (B) The protein alignment of the substituted amino acids resulting from novel mutations. (B, From blast.ncbi.nlm.nih.gov/.) 


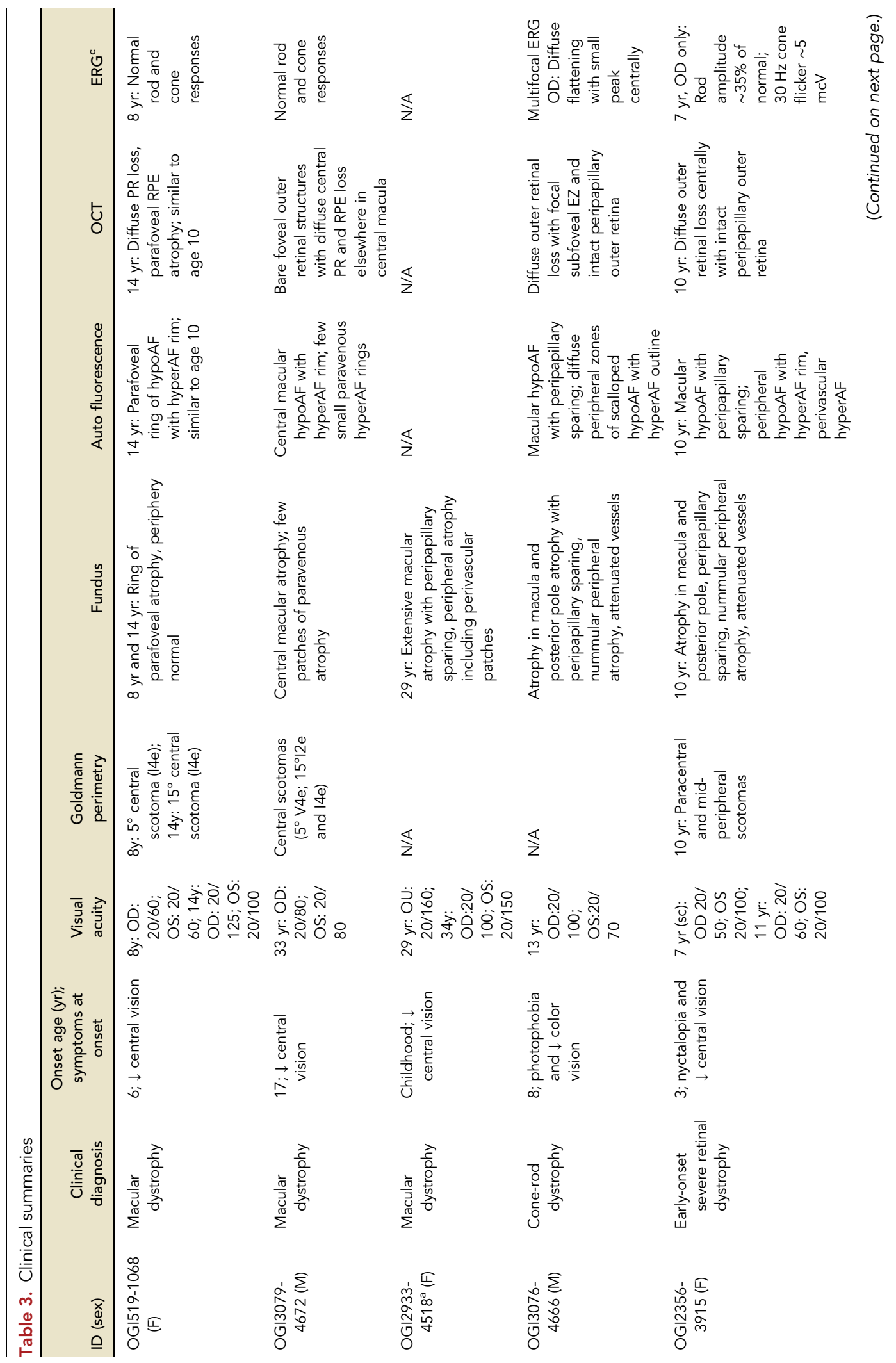




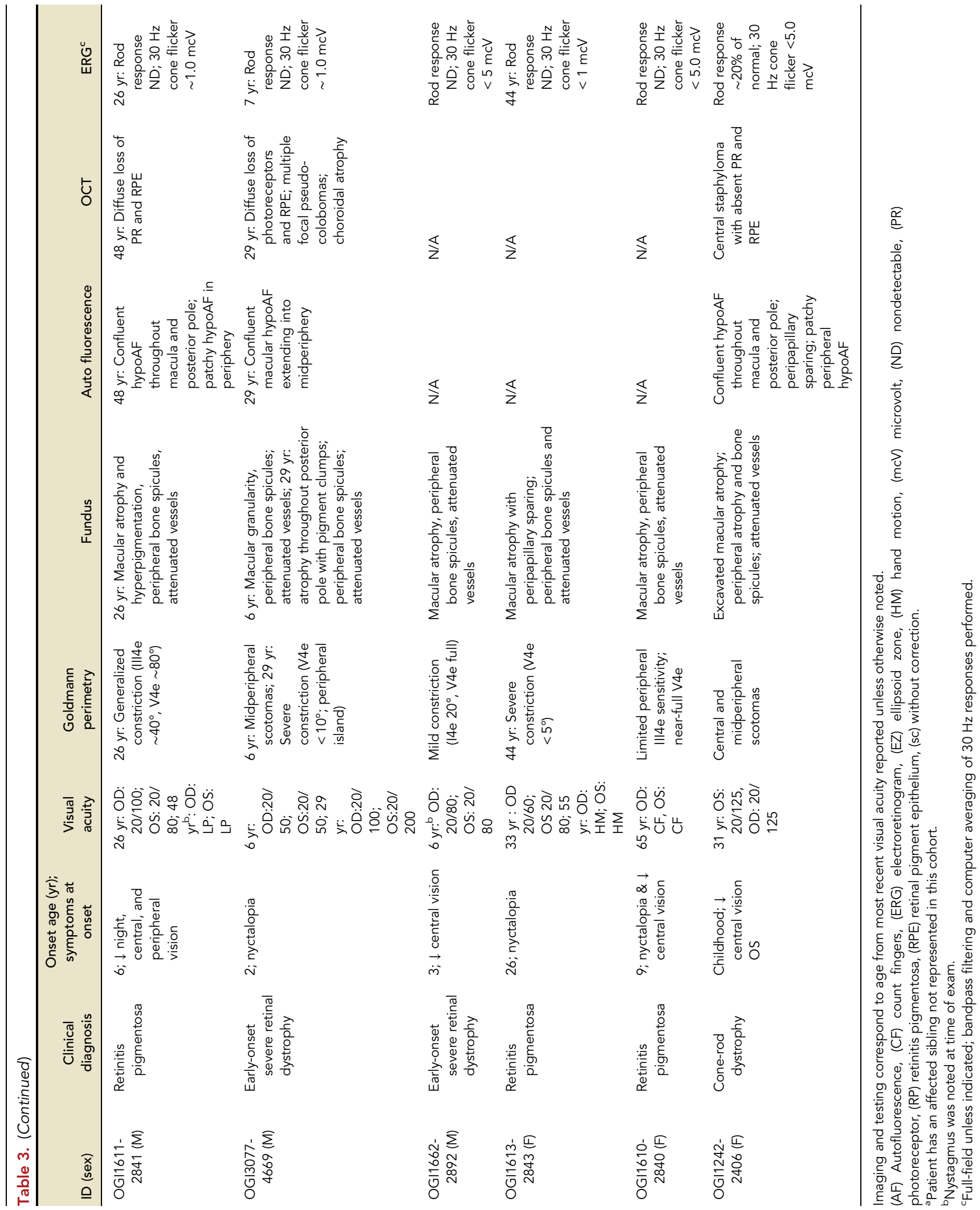



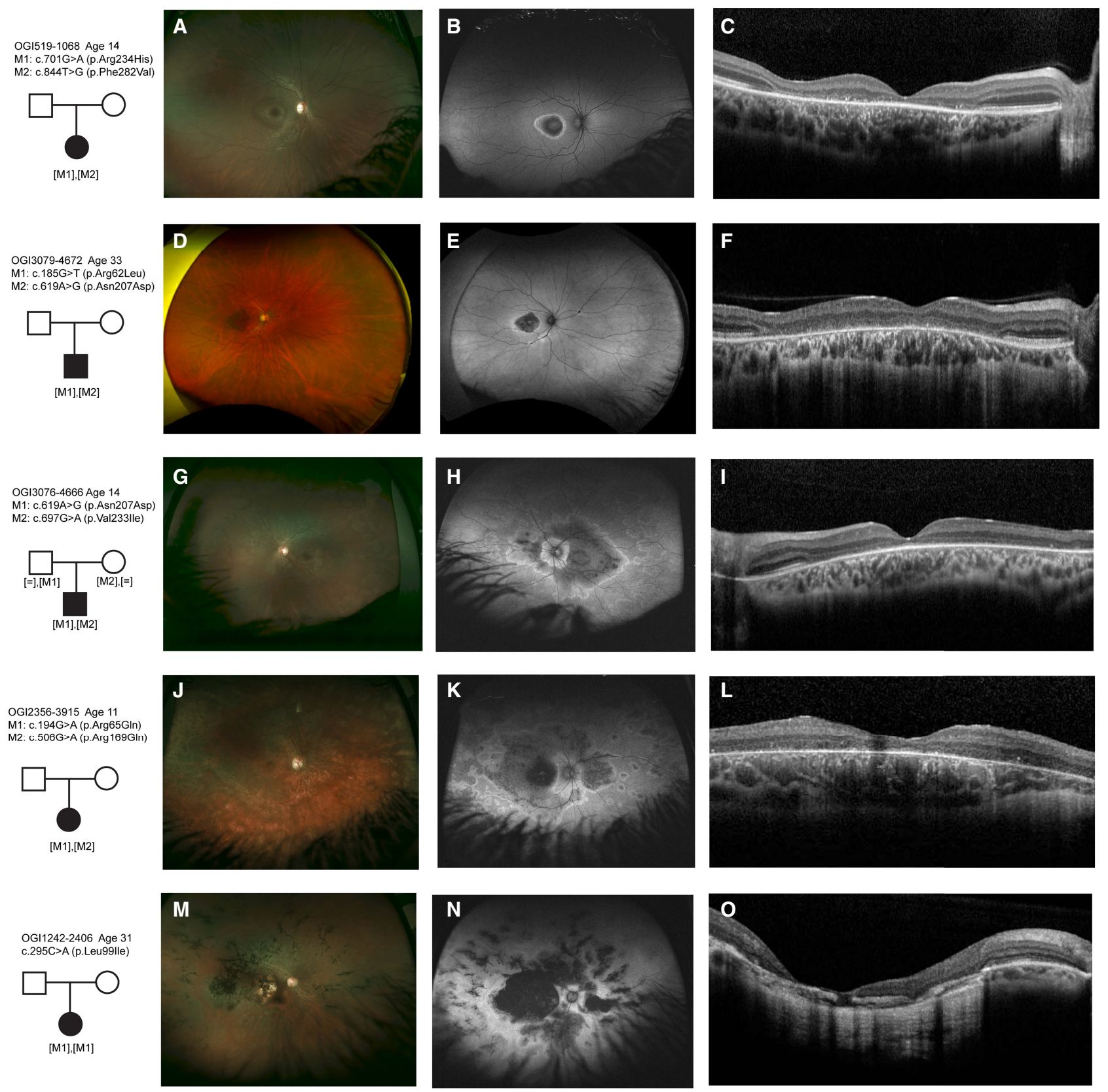

OGI3077-4669 Age 29 c. $146 \mathrm{C}>\mathrm{T}(\mathrm{p} . \mathrm{Thr} 49 \mathrm{Me})$
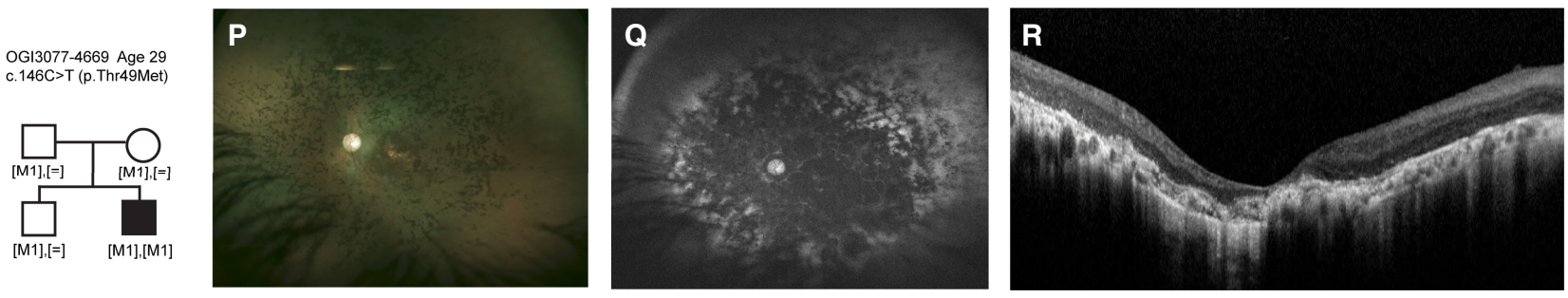

Figure 2. Clinical phenotypes of RDH12-associated patients. Widefield fundus photography, fundus autofluorescence imaging, and optical coherence tomography to demonstrate degree of retinal dystrophy in patients. (A-C) OGl519-1068, age 14; (D-F) OGI3079-4672, age 33; (G-l) OGl3076-4666, age 14; (J-L) OGI2356-3915, age 11; (M-O) OGI1242-2406, age 31; (P-R) OGI3077-4669, age 29. 
only for central scotomas and normal full-field ERG (Table 3). OGI3079-4672, who first noticed decreased central vision at age 17 , still maintained $20 / 80$ visual acuity at age 33 with full visual fields beyond central scotomas and a normal ERG (Table 3; Fig. 2D-F). Both patients carried diagnoses of macular dystrophy and presented with significantly milder phenotype than reported cases of RDH12-associated disease.

Fundus findings in our 11 patients ranged from isolated macular atrophy (Fig. 2A-C) to widespread atrophy throughout the posterior pole and peripheral retina (Fig. 2P,Q). In individuals with predominantly macula-involving disease, a bull's-eye pattern of parafoveal atrophy was seen with a triangular or torpedo-like shape pointing toward the temporal macula (Fig. 2B,E,H). Five patients with macula-predominant disease had peripapillary sparing of the outer retina clinically and on imaging (OGI519-1068, OGI3079-4672, OGI2933-4518 and OGI3076-4666, OGI1242-2406, Table 3; Fig. 2). In more severe disease, the macular atrophy acquired a more excavated appearance (OGI1242-2406 and OGI3077-4669, Fig. 2). The majority of patients in this cohort also had peripheral atrophy (Fig. $2 \mathrm{H}, \mathrm{K}, \mathrm{N}, \mathrm{O}$ ). Widefield fundus autofluorescence was notable for hyperfluorescent outlines around the macula, in nummular areas of atrophy along vessels, and in the periphery (Fig. 2, middle panel). Optical coherence tomography (OCT) demonstrated outer retinal atrophy as well as pseudocolobomatous lesions as previously noted (Fig. 2, right panel; Aleman et al. 2018).

\section{DISCUSSION}

Here, we report 11 subjects with biallelic mutations in $\mathrm{RDH} 12$ that were diagnosed with retinal disease of varying severity including two subjects with a milder phenotype than previously reported. Two individuals were diagnosed with RDH12-related maculopathy, which has not been described previously to be associated with this gene. We identified 15 causal variants in this study, four of which were not previously reported-c.215A $>G$ (p.Asp72Gly), c.362T > C (p.lle121Thr), c.440A > C (p.Asn147Thr), and c.697G >A (p.Val233lle). These novel mutations were located within regions previously shown to be critical to the enzymatic function of the RDH12 enzyme using functional studies (Thompson et al. 2005; Sun et al. 2007). Although variants in other IRD genes have been identified, they were not determined to be the primary cause for disease either because of lack of an additional recessive allele in the same gene or dominant variants that were too common in the population genetic databases (gnomAD) (Karczewski et al. 2019) to be causal. We cannot rule out that these variants may be acting as modifiers, especially those that may act within the same pathway as RDH12.

$\mathrm{RDH} 12$ mutations are associated with well-characterized retinal phenotypes developing in early childhood (Schuster et al. 2007; Mackay et al. 2011; Fahim et al. 2019). Indeed, the majority of this cohort demonstrated severe early-onset disease and also exhibited the previously reported characteristic retinal features. Of the patients with available images, five demonstrated well-demarcated peripapillary sparing of the outer retina and two had diffuse atrophy (Garg et al. 2017). Other previously reported features included pseudocolobomatous changes on OCT (Aleman et al. 2018) as well as "watercolor" hyperautofluorescence tracking along vessels (Fahim et al. 2019).

Recent studies have reported later onset of RDH12-associated disease coinciding with milder phenotypes in patients diagnosed with arRP; however, decreased full-field ERG recordings and peripheral deterioration of the retina was noted (Fahim et al. 2019; Zou et al. 2019). Several cases in this cohort, however, suggest the potential for milder RDH12-associated disease. Three of the 11 patients carried diagnoses of macular dystrophy, and of these, two had disease that was essentially limited to the macula. Although both of these subjects had reduced visual acuity, the macular focus of disease was confirmed by visual fields, normal full-field ERG recordings, and retinal imaging, thus demonstrating a much 
milder phenotype than that seen in other individuals in this study or reported elsewhere (Janecke et al. 2004; Perrault et al. 2004; Thompson et al. 2005; Schuster et al. 2007; Sun et al. 2007; Mackay et al. 2011). Although Xin and colleagues reported a patient with macular findings and hyperautofluorescence along the vessels, the reported patient had reduced cone response amplitudes (Xin et al. 2016). Although one of the two individuals here was an adolescent at the time of last evaluation (OGI519-1068) and thus has an uncertain prognosis, the other (OGI3079-4672) was 33 years old, thus suggesting the possibility of sustained milder disease. Although our study is limited by being retrospective, with follow-up spread out over 40 years (1979-2019) with concomitant heterogeneity of clinical evaluation and available imaging data, overall our findings contribute to clinical understanding of $\mathrm{RDH12}$-associated disease.

Of the four novel variants identified in this study, one, c.697G > A, p.(Val233lle), occurred at a mutational hotspot where c.697G > C p.(Val233Leu), c.697G > T p.(Val233Phe), c.698T > A p.(Val233Asp), and a frameshift c.698insinsGT p.(Val233ValfsX45) have been reported to cause severe retinal disease (Coppieters et al. 2010; Mackay et al. 2011; Lee et al. 2015; Thompson et al. 2017; Jespersgaard et al. 2019). The variant in this study, c.697G > A (p. Val233lle), has been designated as causal in combination with c.619A > G (p.Asn207Asp) in a subject with macular dystrophy (OGI3076-4666), further adding to the heterogeneity in this region.

We have reclassified c.701G >A (p.Arg234His) as likely pathogenic in consideration of functional studies that demonstrated the mutation resulted in decreased expression and significantly reduced catalytic activity compared to wild-type RDH12 (Thompson et al. 2005). This variant most likely results in a hypomorphic allele, which in combination with other missense mutations (p.Phe282Val in OGI519-1068 and p.Asn147Thr in OGI2933-4518), was determined to be causal in both patients (Tables 1 and 2). OGI519-1068 presented with a milder phenotype than OGI2933-4518, who had a typical RDH12-retinal degeneration. This phenotypic difference may be caused by two hypomorphic alleles (p.Arg234His and p.Phe282Val) present in OGI519-1068 and a hypomorphic (p.Arg234His) and a functional null variant (p. Asn147Thr) inherited by OGI2933-4518. Structural and functional studies in bacteria and Drosophila (Benach et al. 1998) have shown that Asn147 is a critical residue in the motif (Asn-Ser-Tyr-Lys) necessary for the coordination of the active site with the water molecule needed for the proton exchange in the reaction. Altering this amino acid resulted in a complete loss of enzymatic activity (Filling et al. 2002), giving confidence that this is likely a loss-of-function variant. The differences in the phenotypes of these patients can also be due to undiscovered genetic modifiers of the severity of the retinal disease. For example, variants in other genes that code for proteins within the same biochemical pathway as the primary gene may affect expression of disease (Badano et al. 2003; Coppieters et al. 2010). As such, ABCA4, coding for a retinal-specific ATP-binding transporter that participates in the visual cycle, is a prime candidate (Zolnikova et al. 2017). Two patients in our study were found to carry rare variants in ABCA4: c.5640T > A, p.Phe1880Leu (OGI3076-4666) and c.2088T > G, p.lle696Met (OGI3077-4669). These were not among the previously reported modifiers, and further studies would need to be undertaken to determine if they have phenotype-modifying effects. Additional polymorphisms in $\mathrm{RDH} 12$ may also act in concert with pathogenic mutations to affect the activity of the underlying protein, thereby altering the phenotype. Two subjects (OGI1611-2841 and OGI3077-4669) were found to be homozygous for the presumed functional null allele c.146T > C (p.Thr49Met), which may be modified by the p.Arg161Gln polymorphism (Thompson et al. 2005; Sun et al. 2007). Given this interaction, we searched for additional rare $\mathrm{RDH} 12$-coding variants and found none present, concluding that these homozygous c.146T > C (p.Thr49Met) mutations alone were responsible for disease in our patients.

It has been suggested that $\mathrm{RDH12}$-associated retinal degeneration has a characteristic and distinguishable phenotype from other retinal disease genes such that sequencing of 
COLD SPRING HARBOR Molecular Case Studies
Novel phenotype associated with RDH12 mutations this locus may be used only to confirm mutations and provide genetic diagnosis (Schuster et al. 2007; Zou et al. 2019). Although most of our cohort falls within these designations and screening of RDH12 alone would suffice, three subjects would have been excluded based on macular-prominent phenotypes. For this reason, a more robust approach to clinical diagnosis that is best achieved with targeted panel testing of all known IRD genes as the standard of care is recommended (Neveling et al. 2013; Consugar et al. 2014). RDH12 mutations can cause a spectrum of retinal degenerations including LCA, CORD, autosomal recessive, autosomal dominant RP, and now macular dystrophy (MD) (Janecke et al. 2004; Perrault et al. 2004; Fingert et al. 2008; Chacon-Camacho et al. 2013; Huang et al. 2016). For this reason, we suggest gene-specific nomenclature rather than a phenotypic-based approach that may be misleading due to some retinal diseases overlap with multiple genes. This approach will help drive research into genetic therapeutic strategies while identifying patients who may benefit from therapies.

\section{METHODS}

\section{Clinical Evaluation}

Ophthalmic evaluations were performed by clinicians experienced in IRDs. Visual acuity was measured using the Snellen and Early Treatment of Diabetic Retinopathy Study (ETDRS) charts. Kinetic perimetry was performed using a Goldmann perimeter. Full-field ERGs were performed using Burian Allen electrodes and a custom ERG system using previously described parameters at MEE (Reichel et al. 1989; Marmor et al. 2009). Retinal structure was assessed with fundus photography (Topcon Medical Systems; Optos), spectral-domain optical coherence tomography (SD-OCT: Spectralis, Heidelberg Engineering; Cirrus, Carl Zeiss), and fundus autofluorescence (FAF; Spectralis, Heidelberg Engineering; Optos).

\section{Genetic Analysis}

DNA extracted from venous blood using the DNeasy Blood and Tissue Kit (QIAGEN) was used for all the sequencing reactions. All samples were sequenced using the Genetic Eye Disease (GEDi) target capture kit, described previously (Consugar et al. 2014). This capture kit was custom designed to target and enrich exons and select deep intronic regions in more than 260 known IRD genes (Retinal Information Network; https://sph.uth.edu) (SureSelect Target Enrichment, Agilent Technologies). Two subjects were sequenced at other facilities (OGI3079-4672 at Prevention Genetics; OGI2356-3915 at the Carver Lab). In addition, WES and data processing were performed by the Genomics Platform at the Broad Institute of MIT and Harvard with an Illumina exome capture (38-Mb target) and sequenced (150-bp paired reads) to cover $>80 \%$ of targets at $20 \times$ and a mean target coverage of $100 \times$. Exome sequencing data was processed through a pipeline based on Picard and mapping done using the BWA aligner to the human genome build 37 (hg19). Variants were called using GATK HaplotypeCaller package version 3.4 (McKenna et al. 2010). The variant call sets were uploaded to segr (http://segr.broadinstitute.org) and analysis performed using the various inheritance patterns. The NGS data from the GEDi panel was analyzed using Genome Analysis Toolkit (GATK) version 3 (McKenna et al. 2010) and annotated using the Variant Effect Predictor (VEP) tool (McLaren et al. 2016) with additional annotations taken from the Genome Aggregation Database (GnomAD; https://gnomad.broadinstitute.org), Genomic Evolutionary Rate Profiling (GERP), SIFT, PolyPhen-2, and retinal expression (Kumar et al. 2009; Davydov et al. 2010; Adzhubei et al. 2013; Farkas et al. 2013). Sequencing coverage details presented in Supplemental Table S2. 
COLD SPRING HARBOR Molecular Case Studies
Novel phenotype associated with RDH12 mutations

\section{Segregation Analysis}

Available samples from family members were used for segregation analysis, and in cases in which no family member samples were available, the variants were phased by cloning and Sanger sequencing. Briefly, genomic DNA was amplified from patients using primers flanking the regions including both variants (Supplemental Table S3). Amplicons were obtained using Takara-La (Takara Bio USA, Inc.) with cycles of $5 \mathrm{~min}$ at $95^{\circ} \mathrm{C} ; 30$ cycles of $10 \mathrm{sec}$ at $98^{\circ} \mathrm{C}$, 8 min at $68^{\circ} \mathrm{C}$, with final extension for $10 \mathrm{~min}$ at $72^{\circ} \mathrm{C}$. All polymerase chain reaction (PCR) was performed on Bio-Rad C1000 Thermocycler (Bio-Rad). PCR-amplified DNA was inserted into the PCR2.1 plasmid, TA cloning kit (Invitrogen) and Sanger sequenced using M13 primers. Sanger sequencing was performed on ABI 3730xI (Applied Biosystems) using BigDye Terminator v3.1 kits (Life Technologies). Sequence analysis was done using SeqManPro (DNAStar; https://www.dnastar.com/software/molecular-biology/), in which variants were considered to be in trans when they were never present on the same clone.

\section{ADDITIONAL INFORMATION}

\section{Data Deposition and Access}

All variants identified in the present study have been submitted to ClinVar (https://www.ncbi .nlm.nih.gov/clinvar/) under accession numbers SCV001146937-SCV001146952.

\section{Ethics Statement}

The study was approved by the institutional review board at the Massachusetts Eye and Ear Infirmary (Human Studies Committee MEE in USA) and the Health Information Portability and Accessibility Act (HIPAA). All aspects of the project adhered to the tenets of the Declaration of Helsinki. Informed consent was obtained from all individuals on whom genetic testing and further molecular evaluations were performed.

\section{Acknowledgments}

Sequencing and analysis were provided by the Broad Institute of MIT and Harvard Center for Mendelian Genomics (Broad CMG) and were funded by the National Human Genome Research Institute, the National Eye Institute, and the National Heart, Lung and Blood Institute grant UM1HG008900 and in part by National Human Genome Research Institute grant R01 HG009141. The authors thank the patients and their family members for their participation in this study and the Ocular Genomics Institute Genomics Core members for their experimental assistance. The authors thank the Exome Aggregation Consortium, the Genome Aggregation Database (GnomAD), and the groups that provided exome variant data for comparison. A full list of contributing groups can be found at http://exac .broadinstitute.org/about and http://gnomad.broadinstitute.org/about.

\section{Author Contributions}

H.A.S. performed experiments and wrote the manuscript. E.M.P. provided clinical data and variant analysis and reviewed the manuscript. K.F. provided clinical analysis and contributed to writing the manuscript. E.Z. prepared samples for NGS. N.E.W. aided in variant analysis. S.P.D. and K.R.C. analyzed sequencing data and reviewed the manuscript. D.N. analyzed sequencing data and reviewed the manuscript. S.M. provided clinical data and reviewed the manuscript. R.M.H. provided clinical analysis and contributed to the writing of the manuscript. E.A.P. contributed to the experimental design and reviewed the manuscript. K.M.B. guided the experimental design, aided in variant analysis, and contributed to writing the manuscript. 
COLD SPRING HARBOR Molecular Case Studies
Novel phenotype associated with RDH12 mutations
Competing Interest Statement

The authors have declared no competing interest.

Received September 11, 2019; accepted in revised form December 5, 2019.

\section{Funding}

This work was supported by grants from the National Eye Institute (R01EY012910 [E.A.P.], R01EY026904 [K.M.B. and E.A.P] and P30EY014104 [MEEl core support]), the Foundation Fighting Blindness (EGI-GE-1218-0753-UCSD [K.M.B. and E.A.P.]), the National Human Genome Research Institute, the National Eye Institute, and the National Heart, Lung and Blood Institute (UM1HG008900, Broad Institute Inc.), and in part by National Human Genome Research Institute grant (R01 HG009141, Daniel MacArthur). S.M. is supported in part by gifts to the Mukai Fund, Massachusetts Eye and Ear, Boston, Massachusetts.

\section{REFERENCES}

Adzhubei I, Jordan DM, Sunyaev SR. 2013. Predicting functional effect of human missense mutations using PolyPhen-2. Curr Protoc Hum Genet Chapter 7: Unit7.20. doi:10.1002/0471142905.hg0720s76

Albert S, Garanto A, Sangermano R, Khan M, Bax NM, Hoyng CB, Zernant J, Lee W, Allikmets R, Collin RWJ, et al. 2018. Identification and rescue of splice defects caused by two neighboring deep-intronic ABCA4 mutations underlying Stargardt disease. Am J Hum Genet 102: 517-527. doi:10.1016/j.ajhg.2018.02.008

Aleman TS, Uyhazi KE, Serrano LW, Vasireddy V, Bowman SJ, Ammar MJ, Pearson DJ, Maguire AM, Bennett J. 2018. RDH12 mutations cause a severe retinal degeneration with relatively spared rod function retinal structure and function in RDH12-LCA. Invest Ophthalmol Vis Sci 59: 5225-5236. doi:10.1167/iovs.18-24708

Badano JL, Kim JC, Hoskins BE, Lewis RA, Ansley SJ, Cutler DJ, Castellan C, Beales PL, Leroux MR, Katsanis N. 2003. Heterozygous mutations in BBS1, BBS2 and BBS6 have a potential epistatic effect on Bardet-Biedl patients with two mutations at a second BBS locus. Hum Mol Genet 12: 1651-1659. doi:10.1093/hmg/ ddg188

Bax NM, Sangermano R, Roosing S, Thiadens AA, Hoefsloot LH, van den Born LI, Phan M, Klevering BJ, Westeneng-van Haaften C, Braun TA, et al. 2015. Heterozygous deep-intronic variants and deletions in $A B C A 4$ in persons with retinal dystrophies and one exonic ABCA4 variant. Hum Mutat 36: 43-47. doi:10 $.1002 /$ humu.22717

Belyaeva OV, Korkina OV, Stetsenko AV, Kim T, Nelson PS, Kedishvili NY. 2005. Biochemical properties of purified human retinol dehydrogenase 12 (RDH12): catalytic efficiency toward retinoids and $\mathrm{C} 9$ aldehydes and effects of cellular retinol-binding protein type I (CRBPI) and cellular retinaldehyde-binding protein (CRALBP) on the oxidation and reduction of retinoids. Biochemistry 44: 7035-7047. doi:10.1021/ bi050226k

Benach J, Atrian S, Gonzàlez-Duarte R, Ladenstein R. 1998. The refined crystal structure of Drosophila lebanonensis alcohol dehydrogenase at 1.9 Å resolution. J Mol Biol 282: 383-399. doi:10.1006/jmbi.1998.2015

Chacon-Camacho OF, Jitskii S, Buentello-Volante B, Quevedo-Martinez J, Zenteno JC. 2013. Exome sequencing identifies $\mathrm{RDH} 12$ compound heterozygous mutations in a family with severe retinitis pigmentosa. Gene 528: 178-182. doi:10.1016/j.gene.2013.07.021

Chen C, Thompson DA, Koutalos Y. 2012. Reduction of all-trans-retinal in vertebrate rod photoreceptors requires the combined action of RDH8 and RDH12. J Biol Chem 287: 24662-24670. doi:10.1074/jbc M112.354514

Consugar MB, Navarro-Gomez D, Place EM, Bujakowska KM, Sousa ME, Fonseca-Kelly ZD, Taub DG, Janessian M, Wang DY, Au ED, et al. 2014. Panel-based genetic diagnostic testing for inherited eye diseases is highly accurate and reproducible, and more sensitive for variant detection, than exome sequencing. Genet Med 17: 253. doi:10.1038/gim.2014.172

Coppieters F, Casteels I, Meire F, De Jaegere S, Hooghe S, van Regemorter N, Van Esch H, Matuleviciene A, Nunes L, Meersschaut V, et al. 2010. Genetic screening of LCA in Belgium: predominance of CEP290 and identification of potential modifier alleles in AHI1 of CEP290-related phenotypes. Hum Mutat 31: E1709E1766. doi:10.1002/humu.21336

Davydov EV, Goode DL, Sirota M, Cooper GM, Sidow A, Batzoglou S. 2010. Identifying a high fraction of the human genome to be under selective constraint using GERP++. PLoS Comput Biol 6: e1001025. doi:10 1371/journal.pcbi.1001025

Fahim AT, Bouzia Z, Branham KH, Kumaran N, Vargas ME, Feathers KL, Perera ND, Young K, Khan NW, Heckenlively JR, et al. 2019. Detailed clinical characterisation, unique features and natural history of autosomal recessive RDH12-associated retinal degeneration. Br J Ophthalmol 103: 1789-1796. doi:10.1136/ bjophthalmol-2018-313580

Farkas MH, Grant GR, White JA, Sousa ME, Consugar MB, Pierce EA. 2013. Transcriptome analyses of the human retina identify unprecedented transcript diversity and 3.5 $\mathrm{Mb}$ of novel transcribed sequence via significant alternative splicing and novel genes. BMC Genomics 14: 486. doi:10.1186/1471-2164-14-486 
Filling C, Berndt KD, Benach J, Knapp S, Prozorovski T, Nordling E, Ladenstein R, Jörnvall H, Oppermann U. 2002. Critical residues for structure and catalysis in short-chain dehydrogenases/reductases. J Biol Chem 277: 25677-25684. doi:10.1074/jbc.M202160200

Fingert JH, Oh K, Chung M, Scheetz TE, Andorf JL, Johnson RM, Sheffield VC, Stone EM. 2008. Association of a novel mutation in the retinol dehydrogenase 12 (RDH12) gene with autosomal dominant retinitis pigmentosa. Arch Ophthalmol 126: 1301-1307. doi:10.1001/archopht.126.9.1301

Garg A, Blumberg DM, Al-Aswad LA, Oll M, Yzer S, Forbes M, Allikmets RL, Bearelly S. 2017. Associations between $\beta$-peripapillary atrophy and reticular pseudodrusen in early age-related macular degeneration. Invest Ophthalmol Vis Sci 58: 2810-2815. doi:10.1167/iovs.16-20343

Haeseleer F, Jang GF, Imanishi Y, Driessen C, Matsumura M, Nelson PS, Palczewski K. 2002. Dual-substrate specificity short chain retinol dehydrogenases from the vertebrate retina. J Biol Chem 277: 4553745546. doi:10.1074/jbc.M208882200

Huang L, Xiao X, Li S, Jia X, Wang P, Sun W, Xu Y, Xin W, Guo X, Zhang Q. 2016. Molecular genetics of conerod dystrophy in Chinese patients: new data from 61 probands and mutation overview of 163 probands. Exp Eye Res 146: 252-258. doi:10.1016/j.exer.2016.03.015

Janecke AR, Thompson DA, Utermann G, Becker C, Hübner CA, Schmid E, McHenry CL, Nair AR, Rüschendorf $\mathrm{F}$, Heckenlively J, et al. 2004. Mutations in RDH12 encoding a photoreceptor cell retinol dehydrogenase cause childhood-onset severe retinal dystrophy. Nat Genetics 36: 850. doi:10.1038/ng1394

Jespersgaard C, Fang M, Bertelsen M, Dang X, Jensen H, Chen Y, Bech N, Dai L, Rosenberg T. 2019. Molecular genetic analysis using targeted NGS analysis of 677 individuals with retinal dystrophy. Sci Rep 9: 1219. doi:10.1038/s41598-018-38007-2

Karczewski KJ, Francioli LC, Tiao G, Cummings BB, Alföldi J, Wang Q, Collins RL, Laricchia KM, Ganna A, Birnbaum DP, et al. 2019. Variation across 141,456 human exomes and genomes reveals the spectrum of loss-of-function intolerance across human protein-coding genes. bioRxiv doi:10.1101/531210

Kumar P, Henikoff S, Ng PC. 2009. Predicting the effects of coding non-synonymous variants on protein function using the SIFT algorithm. Nat Protoc 4: 1073-1081. doi:10.1038/nprot.2009.86

Kurth I, Thompson DA, Ruther K, Feathers KL, Chrispell JD, Schroth J, McHenry CL, Schweizer M, Skosyrski S, Gal A, et al. 2007. Targeted disruption of the murine retinal dehydrogenase gene Rdh12 does not limit visual cycle function. Mol Cell Biol 27: 1370-1379. doi:10.1128/MCB.01486-06

Lee K, Berg JS, Milko L, Crooks K, Lu M, Bizon C, Owen P, Wilhelmsen KC, Weck KE, Evans JP, et al. 2015. High diagnostic yield of whole exome sequencing in participants with retinal dystrophies in a clinical ophthalmology setting. Am J Ophthalmol 160: 354-363.e359. doi:10.1016/j.ajo.2015.04.026

Mackay DS, Dev Borman A, Moradi P, Henderson RH, Li Z, Wright GA, Waseem N, Gandra M, Thompson DA, Bhattacharya SS, et al. 2011. RDH12 retinopathy: novel mutations and phenotypic description. Mol Vis 17: 2706-2716.

Maeda A, Maeda T, Imanishi Y, Sun W, Jastrzebska B, Hatala DA, Winkens HJ, Hofmann KP, Janssen JJ, Baehr $\mathrm{W}$, et al. 2006. Retinol dehydrogenase (RDH12) protects photoreceptors from light-induced degeneration in mice. J Biol Chem 281: 37697-37704. doi:10.1074/jbc.M608375200

Maeda A, Maeda T, Sun W, Zhang H, Baehr W, Palczewski K. 2007. Redundant and unique roles of retinol dehydrogenases in the mouse retina. Proc Natl Acad Sci 104: 19565-19570. doi:10.1073/pnas.0707477104

Marchette LD, Thompson DA, Kravtsova M, Ngansop TN, Mandal MN, Kasus-Jacobi A. 2010. Retinol dehydrogenase 12 detoxifies 4-hydroxynonenal in photoreceptor cells. Free Radic Biol Med 48: 16-25. doi:10.1016/j.freeradbiomed.2009.08.005

Marmor MF, Fulton AB, Holder GE, Miyake Y, Brigell M, Bach M. 2009. ISCEV Standard for full-field clinical electroretinography (2008 update). Doc Ophthalmol 118: 69-77. doi:10.1007/s10633-008-9155-4

McKenna A, Hanna M, Banks E, Sivachenko A, Cibulskis K, Kernytsky A, Garimella K, Altshuler D, Gabriel S, Daly M, et al. 2010. The Genome Analysis Toolkit: a MapReduce framework for analyzing next-generation DNA sequencing data. Genome Res 20: 1297-1303. doi:10.1101/gr.107524.110

McLaren W, Gil L, Hunt SE, Riat HS, Ritchie GRS, Thormann A, Flicek P, Cunningham F. 2016. The Ensembl Variant Effect Predictor. Genome Biol 17: 122. doi:10.1186/s13059-016-0974-4

Neveling K, Feenstra I, Gilissen C, Hoefsloot LH, Kamsteeg EJ, Mensenkamp AR, Rodenburg RJ, Yntema HG, Spruijt L, Vermeer S, et al. 2013. A post-hoc comparison of the utility of sanger sequencing and exome sequencing for the diagnosis of heterogeneous diseases. Hum Mutat 34: 1721-1726. doi:10.1002/humu .22450

Parker RO, Crouch RK. 2010. Retinol dehydrogenases (RDHs) in the visual cycle. Exp Eye Res 91: 788-792. doi:10.1016/j.exer.2010.08.013

Perrault I, Hanein S, Gerber S, Barbet F, Ducroq D, Dollfus H, Hamel C, Dufier JL, Munnich A, Kaplan J, et al. 2004. Retinal dehydrogenase 12 (RDH12) mutations in Leber congenital amaurosis. Am J Hum Genet 75: 639-646. doi:10.1086/424889

Reichel E, Bruce AM, Sandberg MA, Berson EL. 1989. An electroretinographic and molecular genetic study of X-linked cone degeneration. Am J Ophthalmol 108: 540-547. doi:10.1016/0002-9394(89)90431-5 
COLD SPRING HARBOR Molecular Case Studies
Novel phenotype associated with RDH12 mutations

Schulz HL, Grassmann F, Kellner U, Spital G, Ruther K, Jagle H, Hufendiek K, Rating P, Huchzermeyer C, Baier MJ, et al. 2017. Mutation spectrum of the ABCA4 gene in 335 Stargardt disease patients from a multicenter German cohort-impact of selected deep intronic variants and common SNPs. Invest Ophthalmol Vis Sci 58: 394-403. doi:10.1167/iovs.16-19936

Schuster A, Janecke AR, Wilke R, Schmid E, Thompson DA, Utermann G, Wissinger B, Zrenner E, Gal A. 2007. The phenotype of early-onset retinal degeneration in persons with RDH12 mutations. Invest Ophthalmol Vis Sci 48: 1824-1831. doi:10.1167/iovs.06-0628

Stockton DW, Lewis RA, Abboud EB, Al-Rajhi A, Jabak M, Anderson KL, Lupski JR. 1998. A novel locus for Leber congenital amaurosis on Chromosome 14q24. Human Genet 103: 328-333. doi:10.1007/ s004390050825

Sun W, Gerth C, Maeda A, Lodowski DT, Van Der Kraak L, Saperstein DA, Heon E, Palczewski K. 2007. Novel RDH12 mutations associated with Leber congenital amaurosis and cone-rod dystrophy: biochemical and clinical evaluations. Vis Res 47: 2055-2066. doi:10.1016/j.visres.2007.04.005

Thompson DA, Janecke AR, Lange J, Feathers KL, Hubner CA, McHenry CL, Stockton DW, Rammesmayer G, Lupski JR, Antinolo G, et al. 2005. Retinal degeneration associated with RDH12 mutations results from decreased 11-cis retinal synthesis due to disruption of the visual cycle. Hum Mol Genet 14: 3865-3875. doi:10 $.1093 / \mathrm{hmg} / \mathrm{ddi} 411$

Thompson JA, De Roach JN, McLaren TL, Montgomery HE, Hoffmann LH, Campbell IR, Chen FK, Mackey DA, Lamey TM. 2017. The genetic profile of Leber congenital amaurosis in an Australian cohort. Mol Genet Genomic Med 5: 652-667. doi:10.1002/mgg3.321

Xin W, Xiao X, Li S, Zhang Q. 2016. Late-onset CORD in a patient with RDH12 mutations identified by whole exome sequencing. Ophthalmic Genet 37: 345-348. doi:10.3109/13816810.2015.1059457

Zolnikova IV, Strelnikov VV, Skvortsova NA, Tanas AS, Barh D, Rogatina EV, Egorova IV, Levina DV, Demenkova ON, Prikaziuk EG, et al. 2017. Stargardt disease-associated mutation spectrum of a Russian Federation cohort. Eur J Med Genet 60: 140-147. doi:10.1016/j.ejmg.2016.12.002

Zou X, Fu Q, Fang S, Li H, Ge Z, Yang L, Xu M, Sun Z, Li H, Li Y, et al. 2019. Phenotypic variability of recessive RDH12-associated retinal dystrophy. Retina 39: 2040-2052. doi:10.1097/IAE.0000000000002242 


\section{COLD SPRING HARBOR Molecular Case Studies}

\section{Expanding the phenotypic spectrum in RDH12-associated retinal disease}

Hilary A. Scott, Emily M. Place, Kevin Ferenchak, et al.

Cold Spring Harb Mol Case Stud 2020, 6: a004754

Access the most recent version at doi: $10.1101 / \mathrm{mcs} .0004754$

\section{Supplementary http://molecularcasestudies.cshlp.org/content/suppl/2020/01/29/mcs.a004754.D Material C1}

References This article cites 45 articles, 10 of which can be accessed free at: http://molecularcasestudies.cshlp.org/content/6/1/a004754.full.html\#ref-list-1

License This article is distributed under the terms of the Creative Commons Attribution-NonCommercial License, which permits reuse and redistribution, except for commercial purposes, provided that the original author and source are credited.

Email Alerting Receive free email alerts when new articles cite this article - sign up in the box at the Service top right corner of the article or click here. 